septic area, and moreover the colon may be found inseparably united to the kidney. In my case no evil resulted from approaching the renal vessels through the inner mesocolic layer, and this notwithstanding that a search was made for possible renal afferent vessels.

12. Advantages.-Properly carried out there is little or no risk from hæmorrhage, shock, or sepsis. As regards (a) hemorrhage, this method is in great contrast to any form of piecemeal nepbrectomy; $(b)$ it is an aseptio opera. tion which nephrectomy would certainly not be ; and (c) subcapsular or piecemeal nephrectomy is at best a very severe operation; ligature is not so and shock should not occur; there is inappreciable risk as regards possible damage to the colon or other surrounding organs and serous cavities (septic infection).

13. Limitations. - Ligature of the renal vessels may be a very simple proceeding or may be insuperably difficult, and of course there may occur cases where the kidney is so closely adherent to the aorta or the vena cava as to make it impossible to apply a ligature to the vessels. Greig Smith mentions a case where "the aorta and vena cava were so adherent to the kidney that it was found impossible at the autopsy to dissect them apart." I take it that such a condition would be easily recognised through a sufficiently free opening in time to save a blunder. But in the case of the right kidney it might still be possible to ligature the artery by getting at it behind and to the left side of the vena cava, pushing the vessel aside for the purpose of access. Ligature of the artery alone would suffice on laboratory experience to bring about atrophy of the renal epithelium. In the case of the left kidney the renal vein would be accessible and ligature of this alone should bring about a similar result. Von Bergmann mentions a case of Schede's in which an elastic ligature necessarily included a part of the vena cava. The right renal vein is so short (about one inch long) that there would always be danger of opening the septic area in trying to isolate it for purposes of ligature.

Consultations and advic.-An unusual procedure of this sort was naturally not undertaken without first asking the advice of others whose experience would be of great value. First, on several occasions Sir Charles B. Ball very kindly saw the case with me. He quite acquiesced in the view that a further attempt at nephrectomy would not be justifiable, and when at a later date $I$ suggested ligation of the renal vessels he agreed that, though there was no precedent to go upon, it would be worth trying. Finally, I showed the case to him when the sinus had quite healed. To Professor W. H. Thompson, of Trinity College, Dublin, I put the question of the probable result in man of ligature of the renal vessels, and he argued that, from laboratory experience, immediate cessation of urine secretion might be anticipated and then, at an early date, atrophy of the kidney should follow. I had the great advantage of the valuable assistance and wide experience of Dr. W. S. Haughton, surgeon to Steevens's Hospital, Dublin, at two of the attempted nephrectomies, and on each occasion he agreed that the profuse bæmorrhage justified abandonment of the operation. At the final operation (ligature of the renal vessels) I was fortunate in securing the assistance of Dr. R. Atkinson Stoney, senior demonstrator of anatomy, Trinity College, Dublin, and surgeon to the City of Dublin Hospital. My gratitude to these gentlemen is not easily expressed in words.

Conclusion.-In conclusion, though in the first instance this operation was performed when nephrectomy had been attempted and found impossible, I should not hesitate to employ renal vessel ligation in the future as a substitute for nephrectomy where this latter operation promised great difficulty and the likelihood of such severe hæmorrhage as would suffice to turn the scale between life and death in an exhausted patient. Moreover, as a preliminary to a subsequent nephrectomy (a septic operation) an aseptic ligation of the renal vessels would be sound surgery, though I claim that nephrectomy would then be unnecessary, as the ligature would be followed by rapid and permanent cure. Ligature of the renal vessels is surely a great improvement on any form of subcapsular piecemeal nephrectomy or morcellement. The former is a simple, and the latter a very serious, procedure, and both effect the same result.

While quite conscious of the imperfect support that a single successful case affords to a new method, the very rapid, satisfactsry, and permanent cure so obtained seems to warrant my bringing the subject before the notice of the Fellows of the society with some confidence that it may be deemed worthy of criticism at least, and possibly of some degree of approval as to its suitability in cases of a similar nature.

Brief history of case.-The patient was aged 19 years. Sept. 14th, 1902: Ad mitted. Kicked at football previous day, Severe pain in loin Oct. 2nd: Large abscess opened close to left iliac crest; let out pus and urine. Diagnosis : Rupture of ? kidney or ureter.

Jan. 21st, 1903: Extensive empyema evacuated; previous abscess still discharging pus and urine. April 4th: Abscess explored. It extended forward amougst abdominal muscles to near umbilicus, upwards to left pleural cavity, backwards and upwards to left kidney area, downwards into pelvis. Pus in vesical urine. Diagnosed ruptured kidney. urine dischart to Dublin for nephrectomy. 21st: Pyuria; pus and Attempted nephrectomy ; abandoned owing to profuse hæmorrhage removed five calculi. August 6th: Scar in eighth intercostal space opened spontaneously. Nov. 10th: Skiagraph; shadow of calculus in kidney. 12th: Fimpyema scar again opened spontaneously, having kidney. 12th: Fimpyema scar again opened spontaneously, having
remained closed six weeks. Dec. 1st: Operation - Attempted nephreeremained closed six weeks. Dec. 1st: Operation - Attempted nephrecinability to define limits of kidney tissue; three calculi removed; very profuse hæmorrhage.

March 6th, 1904: Skiagraphed; further shadow of calculus. 15th: operation. - Two calculi removed; profuse hæmorrhage, therefore gave up attempt at piecemeal nephrectomy; unable to clamp pedicle; col lapsed and critical condition for many hours. Sept. 26th: Cathelin's separator : Right ureter, urine acid, clear, no pus or blood, no albumin. Left ureter, urine neutral, opaque, "smoky," pus and blood cells. Nov. 17th: No pus in urine; free discharge of pus and urine from sinus. Operation.-Attempted nephrectomy; began by peeling peritoneum from scar tissue ; opened peritoneum inadvertently, at once closed; further separation impossible; removed large calculus from pelvis of kidney, having a rounded process of shape and size of inseparable : very severe hæmorrhage. Saline transfusion adopted. 18th: Sudden profuse hæmorrhage threatening life; condition very critical for some hours; hæmorrhage controlled by gauze packing.

Jan. 29th, 1905: Urine (vesical), c'ear, neutral, no trace of albumin; no pus or blood celis. May 2nd: Urine clear, normal; no shadow of calculus visible: abundant urine and pus from sinus. Cathelin's separator : Right ure er, urine clear, normal; none collected from lef,
ureter. June 13th: Operation - Laparotomy by Lennander's incision. ureter. June isth : pperation - Laparotomy by Lennander's incision. vein ligated, then renal artery tied and divided. No accessory afferent vessels found. August 9 th : Sinus in loin completely closed. 15th: Discharged quite well.

1907. - Letter to say patient remains quite well. Sinus has never reopened or given any troub?e. Until the last operation it had been necessary to apply every day four or more very voluminous dressings ; even these were often quite insufficient to take up all the urine even these were often quite insuficient to take up all the urine
and pus, his bed and clothes occasionally becoming soiled. There was not the least tendency to heal, nor did the amount of discharge and not the least tendency to heal. nor did the amount of
urine ever tend to lessen until after the final operation.

\section{TWO CASES OF INFECTION BY THE PARATYPHOID B BACILLUS.}

\section{By EDWARD A. GATES, M.D. LOND., M.R.C.P. LoND.}

CASE 1. Continued fever; four relapses; venous throms bosis; acute bronohitis; cholecystitis; lentigines; agglutination reaotion with paratyphoid $B$ bacillus. - The patient was a woman, aged 54 years. After a week's malaise she took to her bed on Nov. 26th, 1906, and remained there until March 19th, 1907. The initial symptoms were intense headache, slight epistaxis, vomiting, and fever. There were a few roseolous spots on the chest and abdomen; the tongue was furred ; the spleen was enlarged, descending two fingers' breadth below the costal margin, and the liver one finger's breadth. The right kidney was freely palpable. Constipation was present. The urine gave a well-marked diazo reaction and contained a trace of albumin with, micro scopically, many white cells. On Dec. 3rd the blood serum was sent to the laboratory of the hospital of Santa Maria Nuova to be tested for the reaction with the typhoid bacillus. The report was returned that the reaction was positive. The other features of the case being so strongly in favour of this diagnosis the exact details of the reaction were not demanded until a much later date, when it was found that the test had only been made with a dilution of 1 in 40 , and that it was at the end of three hours that agglutination was observed to have taken place both macroscopically and microscopically. The temperature gradually mounted, reaching its maximum $\left(1.04 \cdot 4^{\circ} \mathrm{F}\right.$.) on Dec. $5 \mathrm{th}$, the pulse-rate varying between 88 and 104. After this the temperature declined gradually with daily oscillations of about $2^{\circ}$, the maximum on Dec, 20th being $100 \cdot 6^{\circ}$. After this it gradually rose again and reached $103.2^{\circ}$ on Jan. 8th, 1907, and continued irregularly raised until the 30 th, when the patient had a severe rigor. Immediately after this for two or three days rhonchi were heard all over both lungs. 
Up to this time, though the fever continued, the patient appeared to be making satisfactory progress, except for the fact that on Jan. 24th she had had pain in the left groin and jnner side of the left thigh, with tenderness over the left femoral vein. This, however, subsided in a couple of days and was not accompanied by any œdema. There was now no headache, the mind was quite clear, the patient was cheerful, the bowels acted well to daily enemata, the urine was norma except for a fine trace of albumin, and food was well taken, consisting of one and a half litres of milk and two eggs daily. During the first fortnight of February the temperatur oscillated between $98^{\circ}$ and $100^{\circ}$ but on the 14th it began again to ascend, reaching $103^{\circ} 6^{\circ}$, with a slight shivering attack on the 20th. The general condition remained excellent. There was no new symptom to account for the rise of temperature. On the $26 \mathrm{th}$ a few fresh rose spots appeared on the abdomen. During February the patient and her nurses observed that she had become extensively freckled on the face, trunk, and limbs, the spots on the last being stains as large as a shilling-piece. The patient declared that she had never before in her life had any freckling of the skin.

On Feb. 27th blood serum was taken and sent to the pathological laboratory of the University of Florence for examination of its reaction on typhoid and paratyphoid bacilli. The examinations were made by Dr. Menini, assistant to Professor Lustig, under Professor Lustig's personal supervision. The report was returned : "Agglutination test executed March 2nd, 1907, with the blood serum of Mrs. - In the dilution of 1 in 100 at the temperature of the room: Negative for the bacillus of typhoid (origin of culture, Berlin). Negative for the paratyphoid bacillus $A$ (laboratory culture). Positive (in about half an hour) for the paratyphoid bacillus B (laboratory culture).'

From Feb. 25th the temperature had been slowly falling, and on March 2nd and 3rd had not risen above $99^{\circ}$. On March 3rd the patient began to have pain round the upper part of the abdomen. This pain was very severe during the night. On the following day the temperature rose with a slight shivering attack to $101 \cdot 8^{\circ}$. There was great tenderness in the right hypochondrium but the outline of the gallbladider could be mapped out, its lower edge reaching to the level of the umbilicus. There were no jaundice and no bile in the urine. The temperature was normal on the 5 th and remained so for ten days. The tenderness soon subsided, but the enlargement of the gall-bladder had not wholly disappeared even on the departure of the patient from Florence in the middle of May. On March 13th fish was allowed and on the 15th minced chicken. On the 16 th the temperature began to rise slightly but never above $100^{\circ}$ and on the $28 \mathrm{th}$ it was normal morning and evening. On the 19th the patient was up for an hour, having been contiruuously in bed until this date from the 26 th of the preceding November. At the beginning of April the temperature was again irregularly, though but slightly, raised, reaching $100.2^{\circ}$ on the 8 th and 9 th, and did not become regularly normal until the 19 th. On the 8 th and 9 th there was some return of the tenderness over the gall-bladder and the patient was kept in bed for three days. After she began to walk the left leg and thigh swelled to some extent, with pitting over the tibia. The swelling was not great and had already become less when the patient left Florence in the middle of May.

CASE 2. Catarrhal jaundice; slight fever; agglutination reaction with paratyphnid $B$ bacillus.-The patient, aged 21 years, who was the daughter of Case 1 and lived in the same apartment, was taken ill with a "bilious attack" on Dec. 7th, 1936, and developed jaundice with symptoms of obstruction of the ontflow of bile. There was slight elevation of temperature, but never above $100^{\circ} \mathrm{F}$. The symptoms rapidly subsided except the slight rise of temperature, which persisted for a week and probably longer, as the patient, feeling quite well, was allowed up and the temperature was no longer taken. During the rest of the winter and spring she was in the best of health. After the blood serum of the mother (Case 1) had given such a decided reaction with the paratyphoid bacillus that of the daughter was also sent for examination at the pathological laboratory of the University and submitted by Dr. Menini to the same tests on March $6 \mathrm{th}$ with identical results-that is, the reaction was negative with typhoid and paratyphoid $A$ bxcilli, but positive in a dilation of 1 in 100 in half an hour with paratyphoid $B$ bacilli.

Florence.

\section{A CASE OF RECURRENT PNEUMO- THORAX.}

By JOHN CARUTHERS SALE, M.R.C.S. ENG., L.R.C.P. LOND.

ON June 3rd, 1906, I was called to see the patient, a welldeveloped woman, aged 21 years, by occupation a draper's assistant, who complained of pain in the right side of the chest and shortness of breath. The history of her illness was as follows. In July, 1901, she had a cough and began to spit up a little blood. She had never previously had a cough except when suffering from an ordinary catarrh. She had whooping-cough in childhood but had never had pleurisy or pneumonia. There was no history of tubercle in the family but her mother suffers from well-marked acromegaly. In August, 1901, about three weeks after she commenced to spit blood, whilst brushing her hair in the morning, she suddenly felt a sharp pain in the right side, which was worse on lifting the right arm. She also bad a cough, was short of breath, and could not lie on her right side. When the pain came on the spitting of blood ceased. She was seen by a medical man who diagnosed pneumothorax. She was in bed for a month and resumed work at the shop in three months, feeling quite well. She was told at the time that she had not got consumption. In A pril, 1902, she had a similar attack which was not so severe. She stayed at home for a week but did not go to bed and did not consult a medical man. In August, 1902, she was again taken with shortness of breath and a dry cough but on this occasion had no pain. In each of the years 1903 and 1904 she had two attacks. On three out of the four attacks she was seen by a medical man who told her that she had pneumothorax but that he could discover no signs of consumption. In February, 1905, whilst staying at a distance she had another attack and was in bed for three weeks. The medical man who attended her there told her that it was another attack of pneumothorax and that her lungs were not diseased.

In April, 1906, she had a further attack but not a severe one. It came on just as she came downstairs. She remained at home for a week but did cot consult anyone. From then she remained in good health until the day on which I saw her. On the night of June 2nd, 1906, she went to bed at 12 o'clock. At 1 A.M. she awoke with pain in the right side and shortness of breath. When $I$ saw her at 6 A.M. her condition was as follows. She was lying on her back; her face was rather flushed; her respirations were 32 per minute; her temperature was $99^{\circ} \mathrm{F}$. and her pulse-rate was 108. She had a slight dry cough. The right side of the chest moved badly but was not immobile. Vocal vibrations were absent over the whole of the right chest. There was hyperresonance all over the right side of the chest; there was no dulness at the base. On auscultation amphoric breathing was heard over the whole of the right chest; the vocal resonance was faint; there was no metallic tinkling; the "bell sound" could be obtained. The heart was not displaced. She remained in bed for three weeks, at the end of which time all the symptoms had subsided. The cough disappeared in a week and at no time was there any expectoration. In two months the patient returned to her employment and at that time on examination her chest appeared to be quite natural. The percussion note and respiratory murmur were equal on both sides, the chest expanded well, and there were no added sounds. Up to the present time--April, 1907-she has remained in good health and runs up and down stairs without any discomfort. She has had no further cough and her lungs, on examination, appear to be quite healthy.

According to the patient's account she has had ten attacks of pneumothorax. I think her account can be relied upon, for, so far as I have been able to ascertain, she can invariably diagnose her own condition with certainty. She knows the onset accurately. There is little shortness of breath as a rule, but there are usually some pain and a dry irritating cough which soon passes off. Between the attacks she has no cough or sputum and she has never had any hæmoptysis since the first attack of pneumothorax. In each attack, so far as I can ascertain, there has been a complete pneumothorax with no sign of fluid at any time during the progress of the case, yet sometimes she is very little affected, at others much distressed. Possibly the size of the opening may account for this variation, a small opening causing a 